\title{
Alcohol dehydrogenases from Kluyveromyces marxianus: heterologous expression in Escherichia coli and biochemical characterization
}

Jing-juan Liang ${ }^{1 *}$, Mei-ling Zhang ${ }^{1}$, Meng Ding ${ }^{1}$, Zhi-mao Mai ${ }^{1}$, San-xing $\mathrm{Wu}^{1}$, Yue Du ${ }^{1}$ and Jia-xun Feng ${ }^{1,2^{*}}$

\begin{abstract}
Background: Kluyveromyces marxianus has recently become a species of interest for ethanol production since it can produce ethanol at high temperature and on a wide variety of substrates. However, the reason why this yeast can produce ethanol at high temperature is largely unknown.

Results: The ethanol fermentation capability of $K$. marxianus GX-UN120 at $40^{\circ} \mathrm{C}$ was found to be the same as that of Saccharomyces cerevisiae at $34^{\circ} \mathrm{C}$. Zymogram analysis showed that alcohol dehydrogenase 1 (KmAdh1) was largely induced during ethanol production, KmAdh4 was constitutively expressed at a lower level and KmAdh2 and KmAdh3 were almost undetectable. The genes encoding the four alcohol dehydrogenases (ADHs) were cloned from strain GX-UN120. Each KmADH was expressed in Escherichia coli and each recombinant protein was digested with enterokinase to remove the fusion protein. The optimum pH of the purified recombinant KmAdh1 was 8.0 and that of KmAdh2, KmAdh3 and KmAdh4 was 7.0. The optimum temperatures of KmAdh1, KmAdh2, KmAdh3 and KmAdh4 were 50, 45,55 and $45^{\circ} \mathrm{C}$, respectively. The $K_{m}$ values of the recombinant KmAdh1 and KmAdh2 were 4.0 and $1.2 \mathrm{mM}$ for acetaldehyde and 39.7 and $49.5 \mathrm{mM}$ for ethanol, respectively. The $V_{\max }$ values of the recombinant KmAdh1 and KmAdh2 were 114.9 and $21.6 \mu \mathrm{mol} \mathrm{min}{ }^{-1} \mathrm{mg}^{-1}$ for acetaldehyde and 57.5 and $1.8 \mu \mathrm{mol} \mathrm{min}{ }^{-1} \mathrm{mg}^{-1}$ for ethanol, respectively. KmAdh3 and KmAdh4 catalyze the oxidation reaction of ethanol to acetaldehyde but not the reduction reaction of acetaldehyde to ethanol, and the $K_{m}$ values of the recombinant KmAdh3 and KmAdh4 were 26.0 and $17.0 \mathrm{mM}$ for ethanol, respectively. The $V_{\max }$ values of the recombinant $\mathrm{KmAdh} 3$ and $\mathrm{KmAdh} 4$ were 12.8 and $56.2 \mu \mathrm{mol} \mathrm{min}{ }^{-1} \mathrm{mg}^{-1}$ for ethanol, respectively.

Conclusion: These data in this study collectively indicate that KmAdh1 is the primary ADH responsible for the production of ethanol from the reduction of acetaldehyde in K. marxianus. The relatively high optimum temperature of KmAdh1 may partially explain the ability of $K$. marxianus to produce ethanol at high temperature. Understanding the biochemical characteristics of KmAdhs will enhance our fundamental knowledge of the metabolism of ethanol fermentation in K. marxianus.
\end{abstract}

Keywords: Alcohol dehydrogenase, Characterization, Expression, Gene cloning, Kluyveromyces marxianus

\footnotetext{
* Correspondence: jjliang@gxu.edu.cn; jiaxunfeng@sohu.com

'College of Life Science and Technology, Guangxi University, 100 Daxue Road, Nanning, Guangxi 530004, P. R. China

${ }^{2}$ State Key Laboratory for Conservation and Utilization of Subtropical Agro-bioresources, Guangxi University, 100 Daxue Road, Nanning, Guangxi 530004, P. R. China
}

\section{Biomed Central}

(c) 2014 Liang et al.; licensee BioMed Central Ltd. This is an Open Access article distributed under the terms of the Creative Commons Attribution License (http://creativecommons.org/licenses/by/2.0), which permits unrestricted use, distribution, and reproduction in any medium, provided the original work is properly credited. The Creative Commons Public Domain Dedication waiver (http://creativecommons.org/publicdomain/zero/1.0/) applies to the data made available in this article, unless otherwise stated. 


\section{Background}

Kluyveromyces marxianus is a sister species to the better-known $K$. lactis [1]. A large number of studies on $K$. lactis have mainly focused on its lactose metabolism and use as a model for non-conventional yeasts [2]. In contrast, scientific literature about the fundamental aspects of $K$. marxianus is relatively scarce [1]. Recently, $K$. marxianus has gained increasing attention since some of its traits are desirable for biotechnological applications. These traits include the fastest growth rate of any eukaryotic microbe, thermotolerance, secretion of native enzymes such as inulinase, $\beta$-galactosidase and pectinase, and production of ethanol $[1,3]$.

$K$. marxianus is now being investigated as an alternative to Saccharomyces cerevisiae for ethanol production, especially in simultaneous saccharification and fermentation (SSF) or simultaneous saccharification and co-fermentation (SSCF) processes, since it can produce ethanol at higher temperatures and on a wider variety of substrates including xylose [3-5]. It has been reported to be able to grow at $45^{\circ} \mathrm{C}$ and even $52^{\circ} \mathrm{C}$ and to produce ethanol at temperatures above $40^{\circ} \mathrm{C}[4,6,7]$. S. cerevisiae, in contrast, is unable to ferment xylose and has an optimum growth temperature ranging from 30 to $34^{\circ} \mathrm{C}$ [8]. The enzymatic hydrolysis during SSF or SSCF processes is usually conducted at approximately $50^{\circ} \mathrm{C}$, and the products formed during the hydrolysis step in SSCF include hexoses and pentoses. The traits of $K$. marxianus make it suitable for use in SSCF processes involving cellulosic biomass $[9,10]$.

Yeast alcohol dehydrogenase $(\mathrm{ADH})$ catalyzes the final metabolic step in ethanol fermentation, and thus plays an important role. The ADH systems of $S$. cerevisiae and $K$. lactis were studied extensively and seven $S c A D H$ genes (ScADH1 to $S C A D H 7$ ) and four KlADH genes (KlADH1 to $K l A D H 4)$ have reportedly been cloned [11-14]. There are only a few scientific papers on the ADH systems of $K$. marxianus. Recently, the complete genome sequence of K. marxianus var. marxianus KCTC 17555 was determined and four ADH-encoding genes were annotated in the genome [15]. Two genes, $K m A D H 1$ and $K m A D H 2$, were cloned from $K$. marxianus ATCC 12424, while other two genes, $K m A D H 3$ and $K m A D H 4$, were cloned from K. marxianus DMKU 3-1042 [12,16-18]. However, heterologous expression of the four genes and the biochemical properties of the KmAdhs have not been reported yet.

The $K$. marxianus GX-UN120 strain obtained in our laboratory is an excellent ethanol producer at high temperature and produced $69 \mathrm{~g} / \mathrm{L}$ of ethanol when fermenting $150 \mathrm{~g} / \mathrm{L}$ of glucose at $40^{\circ} \mathrm{C}$ [19]. Determining the biochemical characteristics of the ADHs of GX-UN120 will help to explain why it can produce high levels of ethanol at high temperature. In the present study, the genes encoding the four KmAdhs of GX-UN120 were cloned and individually overexpressed in E. coli, and the biochemical characteristics of each purified KmAdh were investigated. Understanding the biochemical characteristics of the KmAdhs of $K$. marxianus will enhance our fundamental knowledge of the ADH systems and the metabolism of ethanol fermentation in $K$. marxianus.

\section{Results}

\section{Growth and ethanol fermentation characteristics of K. marxianus GX-UN120}

K. marxianus GX-UN120 is an excellent ethanol-producing mutant strain that was converted from the wild-type strain GX-15 by alternately treatment with UV irradiation and NTG for two cycles. When fermenting $150 \mathrm{~g} / \mathrm{l}$ of glucose, the ethanol yield of GX-UN120 was $69 \mathrm{~g} / \mathrm{l}$ which was $20 \%$ higher than that of GX-15. However, the ADH activity of GX-UN120 was not significantly higher than that of GX-15 [19]. The nucleotide sequence of $K m A D H 1$ in GX-UN120 (KF678864) was not different to that in GX-15 (JF709970). The growth and ethanol fermentation characteristics of GX-UN120 were determined compared with those of $S$. cerevisiae Angel, which is a commercial ethanol producer in China. The optimum temperatures for growth and ethanol fermentation of GX-UN120 were $35-40^{\circ} \mathrm{C}$ and $40^{\circ} \mathrm{C}$, respectively, whereas that of Angel was $28-34^{\circ} \mathrm{C}$. GX-UN120 grew well even at $45^{\circ} \mathrm{C}$, whereas Angel was not able to grow when the temperature was over $45^{\circ} \mathrm{C}$ (Figure $1 \mathrm{a}$ and $\mathrm{b}$ ). The time courses for ethanol formation in $150 \mathrm{~g} / \mathrm{L}$ glucose by GX-UN120 at $40^{\circ} \mathrm{C}$ and Angel at $34^{\circ} \mathrm{C}$ are shown in Figure 1c. The time taken for GX-UN120 to completely consume the glucose and reach its maximum ethanol yield was the same as that for Angel. Both yeasts consumed the glucose completely within $72 \mathrm{~h}$. At that time the maximum ethanol concentration and ethanol yield coefficient of GX-UN120 were $67.6 \mathrm{~g} / \mathrm{L}$ and $0.45 \mathrm{~g} / \mathrm{g}$, respectively, and those of Angel were $67.7 \mathrm{~g} / \mathrm{L}$ and $0.45 \mathrm{~g} / \mathrm{g}$, respectively.

\section{Analysis of the expression of $\mathrm{KmADHs}$ in $\mathrm{K}$. marxianus GX-UN120}

The translational levels of $K m A D H$ genes in GX-UN120 were determined through the analysis of zymograms of the $\mathrm{ADH}$ isozymes at different fermentation phases (the lag, exponential and stationary phases) in YPD containing $150 \mathrm{~g} / \mathrm{L}$ of glucose (Figure 2). The results indicated that $K m A D H 1$ was weakly expressed at the lag phase and largely expressed at the exponential phase, and its expression level decreased at the stationary phase. $K m A D H 4$ was constitutively expressed during all phases. The expression levels of $K m A D H 2$ and $K m A D H 3$ were not detectable.

Cloning and sequence analysis of the genes encoding the four KmADHs from $K$. marxianus GX-UN120

The four genes encoding ADHs, KmADH1, KmADH2, $K m A D H 3$ and $K m A D H 4$, were cloned from GX-UN120 

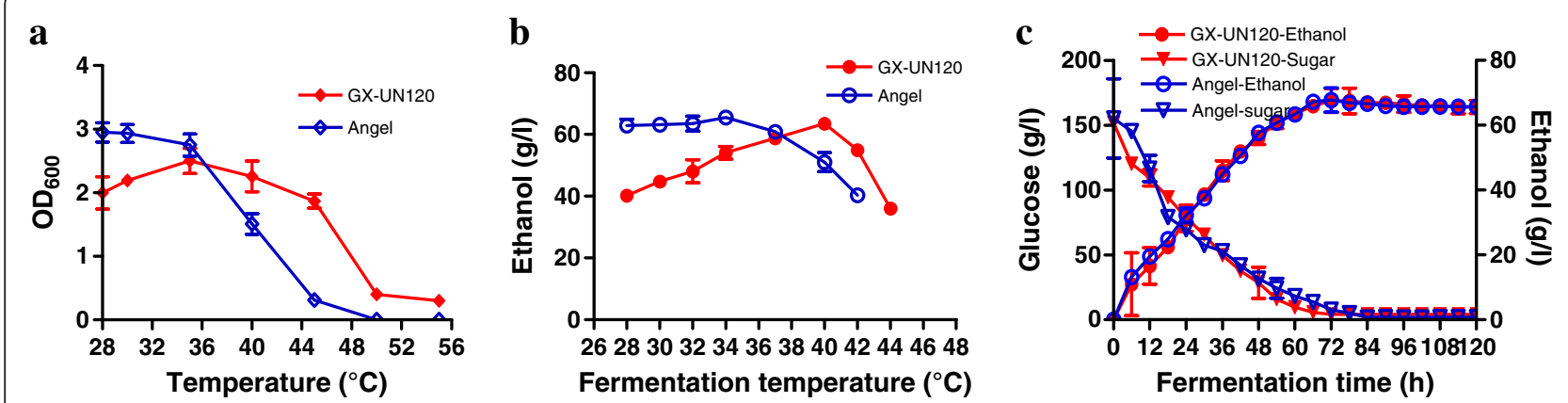

Figure 1 The growth and ethanol fermentation characteristics of $K$. marxianus GX-UN120 and S. cerevisiae Angel. Exponential phase cultures of GX-UN120 and Angel were used to inoculate YPD medium containing $20 \mathrm{~g} / \mathrm{L}$ glucose to a final OD 600 Of 0.2 or fermentation medium containing $150 \mathrm{~g} / \mathrm{L}$ glucose with 10\% of the inoculum. (a) Growth in YPD medium containing $20 \mathrm{~g} / \mathrm{L}$ glucose for $24 \mathrm{~h}$ without shaking. (b) Ethanol fermentation was carried out in $150 \mathrm{~g} / \mathrm{L}$ glucose at different temperatures for $72 \mathrm{~h}$ without shaking. (c) The time course of ethanol fermentation was recorded in $150 \mathrm{~g} / \mathrm{L}$ glucose at $40^{\circ} \mathrm{C}$ (GX-UN120) or $34^{\circ} \mathrm{C}$ (Angel) without shaking. Experiments were performed in triplicate and the results are given as mean values with error bars indicating standard deviations.

and sequenced. The open reading frames (ORFs) of the four ADH genes were, respectively, 1047, 1047, 1128 and $1140 \mathrm{bp}$ and the deduced amino acid sequences were 348, 348, 375 and 379 amino acids, respectively. The deduced amino acid sequences of the four KmAdhs

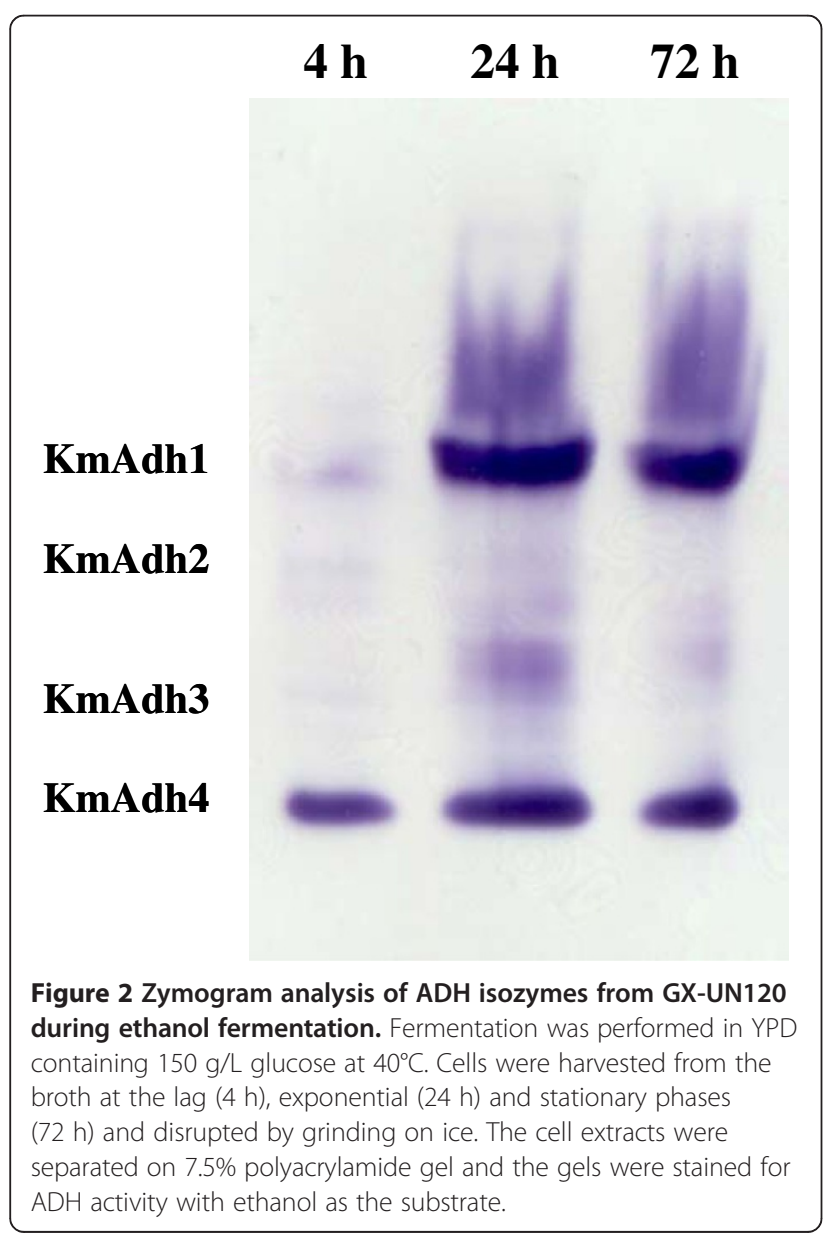

from GX-UN120 shared $98 \%$ to $99 \%$ identity with the corresponding four genes of ATCC 12424 and more than $80 \%$ identity with the ADHs of K. lactis, $K$. wickerhamii, $S$. cerevisiae, S. carlsbergensis, S. kluyveri, S. pastorianus and Hansenula polymorpha [11-14,16,17,20-23]. There are five amino acid residues difference in the deduced amino acid sequence of KmADH1 in GX-UN120 and KmADH1 in ATCC 12424, they are N15H, G239V, T328S, S334V and I339V. In KmADH2, the different amino acid residues are H315N and I338V. In KmADH3, the different amino acid residues are E233D and Q240E. In $\mathrm{KmADH} 4$, the different amino acid residues are N268S, V360I and S378A. All these amino acid residues are not in the groups directly involved in catalysis.

The phylogenetic analysis of the amino acid sequences of the KmAdhs and yeast ADHs (Additional file 1: Table S1) in Figure 3 reveals that KmAdh1 of GX-UN120 is closely grouped with Adh1 from K. marxianus ATCC 12424, K. marxianus DMKU3-1042 and K. wickerhamii and Adh2 from $K$. lactis, and KmAdh2 is grouped with Adh2 from $K$. marxianus ATCC 12424, whereas KmAdh3 and KmAdh4 are closely grouped with Adh3 and Adh4 from K. marxianus ATCC 12424, K. marxianus DMKU3-1042, K. wickerhamii and $K$. lactis.

The multiple amino acid sequence alignments of KmAdhs with ADHs from other yeasts (Additional file 1: Table S1) reveal that KmAdh1 and KmAdh2 do not possess but KmAdh3 and KmAdh4 do possess the $\mathrm{N}$-terminal mitochondrion targeting sequence (Figure 4). These results indicate that KmAdh1 and KmAdh2 are cytoplasmic ADHs, whereas KmAdh3 and KmAdh4 are mitochondrial ADHs. Several conserved motifs of the microbial group I ADHs were found in the KmADHs, including $\mathrm{Asp}^{202}$ in KmAdh1 and KmAdh2, $\operatorname{Asp}^{229}$ in KmAdh3 and $\mathrm{Asp}^{233}$ in KmAdh4, which determine the $\mathrm{NAD}^{+}$specificity. This suggests that KmAdhs are NAD- 


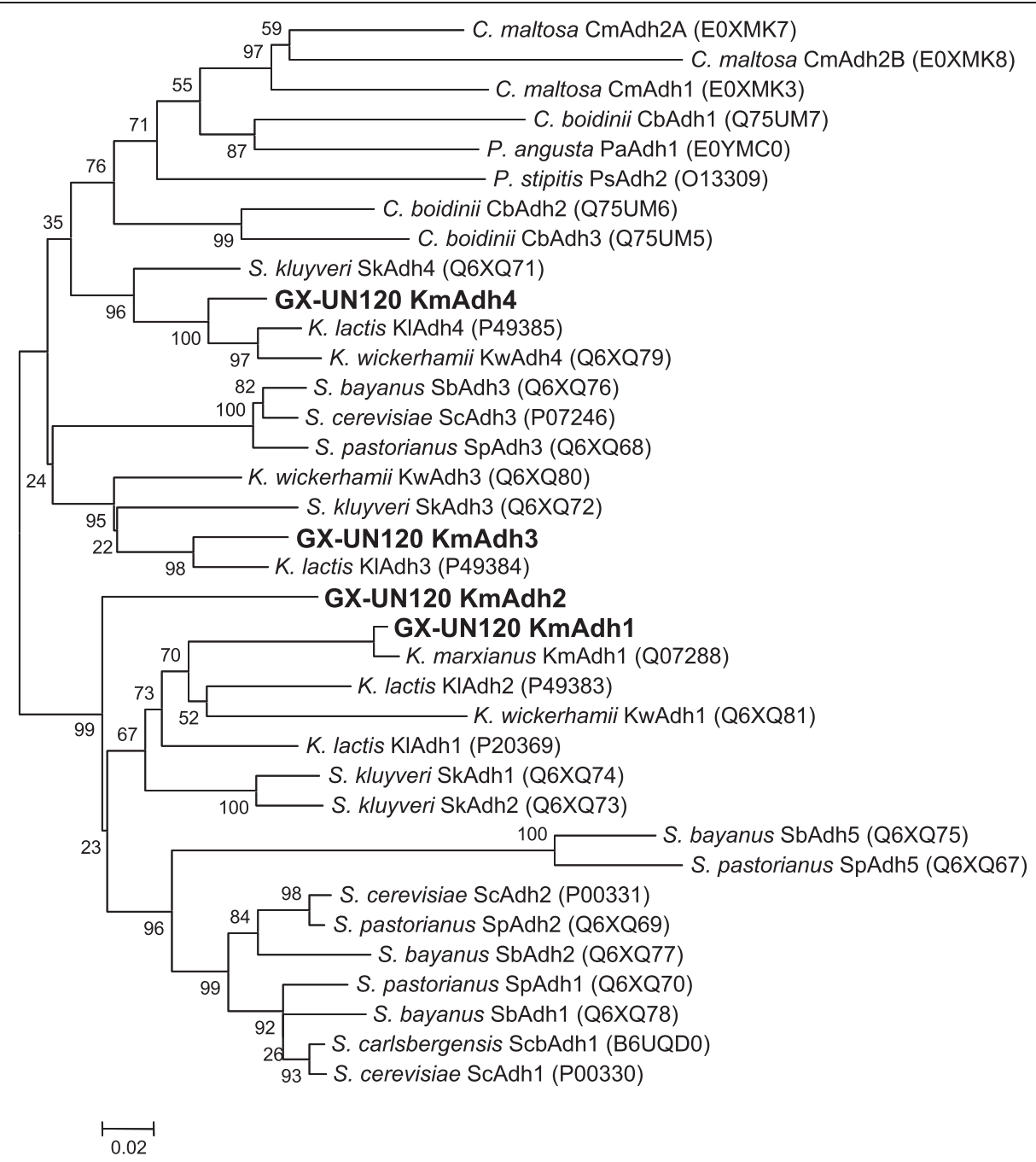

Figure 3 Phylogenetic analysis of KmAdhs of GX-UN120. The sequences were aligned to generate an unrooted phylogenetic tree with MEGA 4.0 using the neighbor-joining method. Branch support values from 1000 bootstrap replications are presented beside each node and a Poisson correction was carried out. GenBank accession numbers are shown in brackets after each enzyme name. All proteins included in the analysis were enzymatically characterized as alcohol dehydrogenases. References are listed in Additional file 1: Table S1 in the supplementary materials.

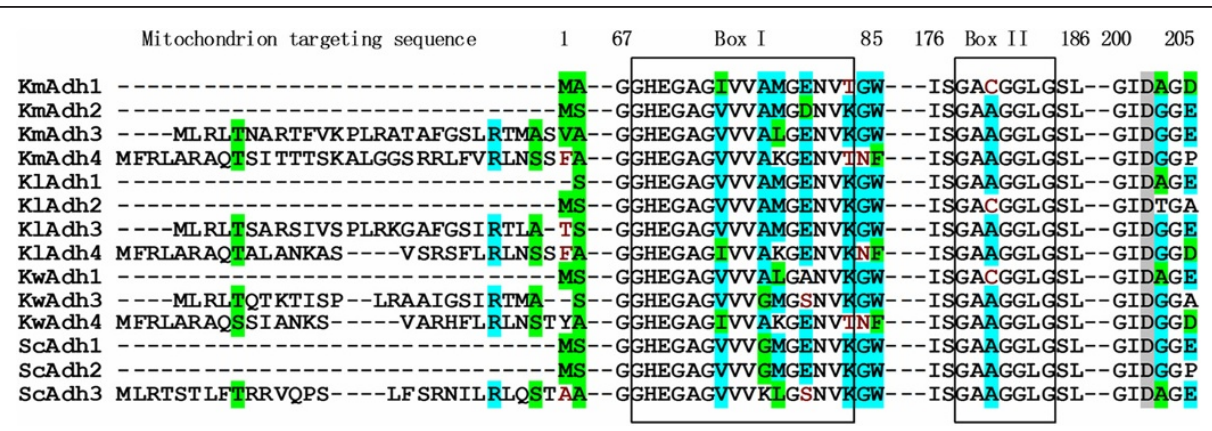

Figure 4 Alignment of the conserved amino acid residues and structurally conserved regions of the KmAdhs. Alignment was done using the Vector NTI program. The protein codes correspond to those listed in Additional file 1: Table S1 in the supplementary material. Asp residues in deep grey determine the specificity for $\mathrm{NAD}^{+}$. Residues in box I and box II indicate $\mathrm{Zn}^{2+}$-binding and $\mathrm{NAD}^{+}$-binding moieties, respectively. KmAdh, alcohol dehydrogenase from K. marxianus; KIAdh, alcohol dehydrogenase from K. lactis; KwAdh, alcohol dehydrogenase from K. wickerhamii;; ScAdh, alcohol dehydrogenase from S. cerevisiae. 
dependent $\mathrm{ADHs}$ similar to the ADHs of other yeasts [24]. The NAD ${ }^{+}$-binding motifs of the KmAdhs are GAG/ CGGLG (BoxII), similar to those in ADHs of other yeasts $[12,21,25] . \mathrm{Zn}^{2+}$-binding residues, which are known to be essential for enzyme catalytic activity and structure, and the $\mathrm{Zn}^{2+}$-binding consensuses were also found (Box I).

\section{Expression and purification of the recombinant KmADHs}

The four cloned ADH genes were expressed in E. coli Rosetta DE3. The recombinant KmAdhs were purified and then digested with enterokinase light chain. A clear, single band for each of the KmAdh1, KmAdh2, KmAdh3 and KmAdh4 fusion proteins corresponding to about 58, 59,49 and $60 \mathrm{kDa}$, respectively, was clearly seen on SDSPAGE (Figure 5). The purified recombinant KmAdh1, KmAdh3 and KmAdh4, after digestion with enterokinase light chain, had molecular masses corresponding to about 48, 48 and $49 \mathrm{kDa}$, respectively, as observed by SDSPAGE (Figure 5). The purified recombinant KmAdh2 had a molecular mass of about $48 \mathrm{kDa}$ (data not shown). The molecular masses of the purified KmAdh1, KmAdh2, KmAdh3 and KmAdh4, as determined by HPGPC, were about 190, 190, 190 and $200 \mathrm{kDa}$, respectively (data not shown). These results indicate that each of the four KmAdhs of GX-UN120 is active as a homotetramer.

\section{Biochemical characterization of the recombinant KmAdhs}

The purified recombinant KmAdhs without tags were used for the characterization of enzymatic properties. The specific ADH activities of KmAdh1 and KmAdh2 were 102.5 and $19.3 \mathrm{U} / \mathrm{mg}$ for acetaldehyde and 47.5 and $1.5 \mathrm{U} / \mathrm{mg}$ for ethanol, respectively. Those of KmAdh3 and KmAdh4 were, respectively, 10.1 and $46.0 \mathrm{U} / \mathrm{mg}$ for ethanol and no activities were detected for acetaldehyde. ADH activities were investigated with $\mathrm{NAD}^{+}$or $\mathrm{NADP}^{+}$and $\mathrm{NADH}$ or $\mathrm{NADPH}$ as cofactors to determine cofactor preference.
The specific activities of KmAdhs with $\mathrm{NAD}^{+}$and NADH were 70-80 times and 50-60 times higher than those with $\mathrm{NADP}^{+}$and NADPH, respectively. These data indicate that KmAdhs prefer $\mathrm{NAD}^{+}$and $\mathrm{NADH}$ as cofactor. KmAdh1 showed activity in the range of $\mathrm{pH}$ 5.0-9.0 when acetaldehyde was the substrate and $\mathrm{pH}$ 6.0-9.0 when ethanol was used as the substrate. KmAdh2, KmAdh3 and KmAdh4 showed activities in the range of $\mathrm{pH}$ 6.0-10.0. Beyond these $\mathrm{pH}$ ranges, the activities of the enzymes were completely lost. The optimum $\mathrm{pH}$ of KmAdh1 was measured as 8.0, while those of KmAdh2, KmAdh3 and KmAdh4 were 7.0 (Figure 6a). KmAdh1, KmAdh2, KmAdh3 and KmAdh4 were relatively stable at $\mathrm{pH}$ 7.09.0, 5.0-9.0, 6.0-9.0 and 6.0-8.0, respectively. They retained more than $60 \% \mathrm{ADH}$ activity when incubated at the corresponding $\mathrm{pH}$ ranges for $24 \mathrm{~h}$ (Figure 6b). KmAdh1, KmAdh2 and KmAdh4 showed significant activities between the temperatures of 35 and $55^{\circ} \mathrm{C}$, while $\mathrm{KmAdh} 3$ showed significant activity between 35 and $65^{\circ} \mathrm{C}$. The optimum temperatures of KmAdh1, KmAdh2, KmAdh3 and $\mathrm{KmAdh} 4$ were $50,45,55$ and $45^{\circ} \mathrm{C}$, respectively (Figure 6c). KmAdh1 and KmAdh3 were relatively stable in the temperature range of 30 to $45^{\circ} \mathrm{C}$, while $\mathrm{KmAdh} 2$ and $\mathrm{KmAdh} 4$ were relatively stable at 30 to $40^{\circ} \mathrm{C}$. The $\mathrm{ADH}$ activities decreased sharply above $45^{\circ} \mathrm{C}$ and were completely lost above $60^{\circ} \mathrm{C}$ (Figure 6d).

The kinetic properties of the KmAdhs were determined and are summarized in Table 1 . The $K_{\mathrm{m}}$ values of KmAdh1 and KmAdh2 for ethanol were about 10- and 42-fold higher, respectively, than those for acetaldehyde, while the $V_{\max }$ values for acetaldehyde were about 2and 12-fold higher, respectively, than those for ethanol. The turnover numbers $\left(K_{\text {cat }}\right)$ of KmAdh1 and KmAdh2 for acetaldehyde were 2- and 12-fold and the catalytic efficiencies $\left(K_{\text {cat }} / K_{\mathrm{m}}\right)$ were 20 - and 520 -fold higher than those for ethanol, respectively. These results indicate

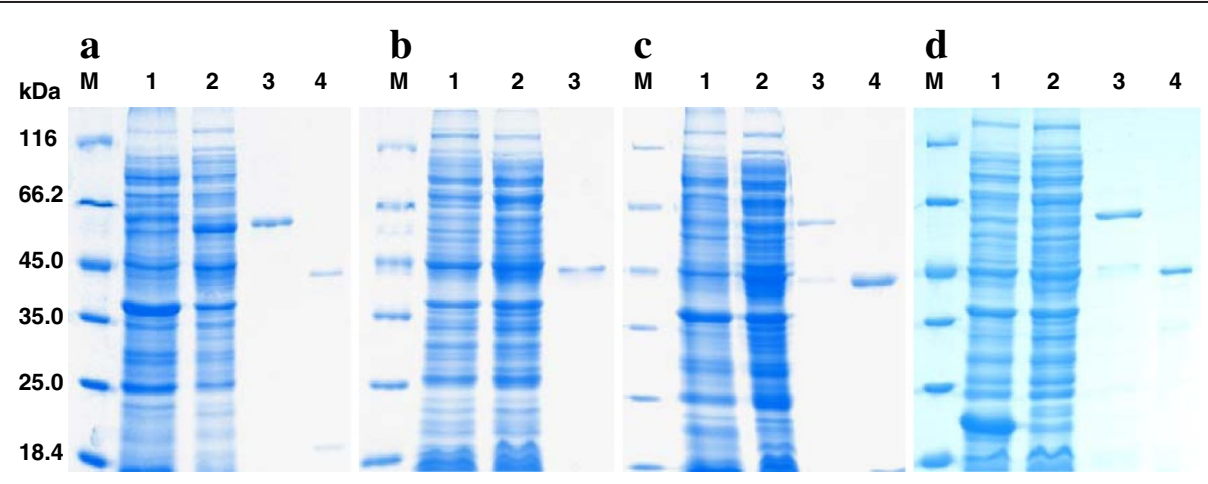

Figure 5 Electrophoresis of KmAdhs from K. marxianus GX-UN120. SDS-PAGE analysis on 10\% polyacrylamide gel stained with Coomassie light blue. a, KmAdh1; b, KmAdh2; c, KmAdh3; d, KmAdh4. Lane M, protein molecular weight markers (116.0, 66.2, 45.0, 35.025 .0 and 18.4 kDa). Lane 1, proteins of E. coli Rosetta DE3 harboring the empty plasmid pET-32a(+) in $\mathbf{a}, \mathbf{c}$, d and empty pET-30a(+) in b; lane 2, proteins of E. coli Rosetta DE3 harboring the plasmids pET-32a(+)-KmADH1, pET-32a(+)-KmADH3 and pET-32a(+)-KmADH4 in $\mathbf{a}, \mathbf{c}$ and $\mathbf{d}$ and pET-30a(+)-KmADH2 in b; lane 3, the purified recombinant KmAdhs fusion proteins; lane 4, the purified KmAdhs. The recombinant fusion proteins and proteins after digestion with enterokinase light chain were purified with Co-NTA chromatography. 

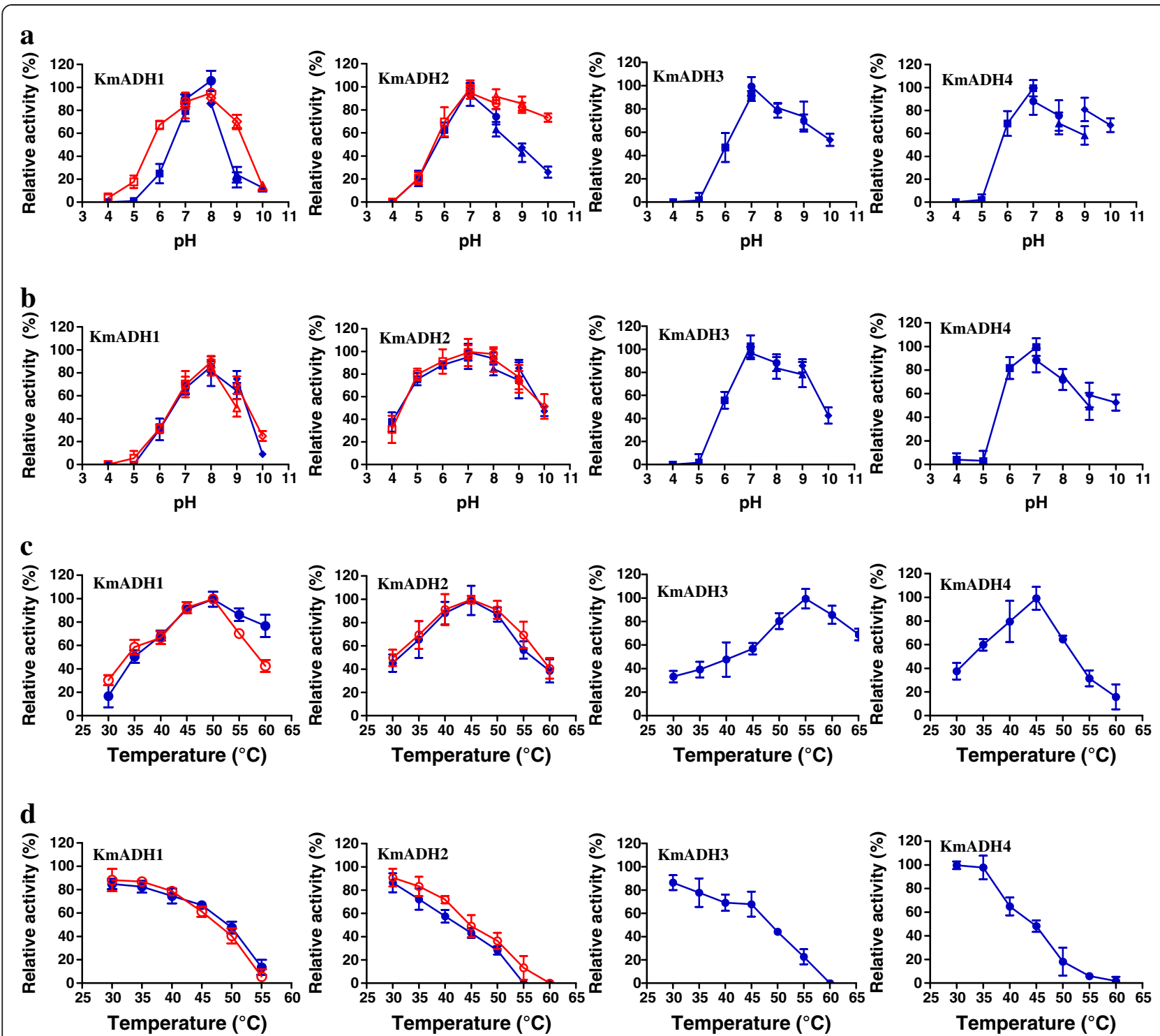

Figure 6 Effects of $\mathrm{pH}$ and temperature on enzyme activities of KmAdhs. a Determination of the optimal pH of the KmAdhs. Enzyme assays were performed at the indicated $\mathrm{pH}$ at $40^{\circ} \mathrm{C}$ using ethanol (closed symbols) and acetaldehyde (open symbo/s) as substrates. squares, $50 \mathrm{mM}$ citrate-phosphate buffer (pH 4.0-7.0); circles, 50 mM sodium-phosphate buffer ( $\mathrm{pH}$ 6.0-8.0); triangles, $50 \mathrm{mM}$ Tris-HCl buffer (pH 8.0-9.0); diamonds, $50 \mathrm{mM}$ glycine- $\mathrm{NaOH}$ buffer (pH 9.0-10.0). b pH stability of the KmAdhs. Enzyme activity was measured under optimal conditions (50 mM sodium-phosphate buffer of $\mathrm{pH} 7.0,40^{\circ} \mathrm{C}$ ) after the enzyme was incubated in the indicated buffers at $4^{\circ} \mathrm{C}$ for $24 \mathrm{~h}$. c Determination of the optimal temperatures of the KmAdhs. Activity was measured at pH 7.0 (50 mM sodium-phosphate buffer) at the indicated temperatures. $\mathbf{d}$ Thermal stability of KmAdhs. Enzyme activity was measured under optimal conditions ( $50 \mathrm{mM}$ sodium-phosphate buffer of $\mathrm{pH} 7.0,40^{\circ} \mathrm{C}$ ) after the enzyme had been incubated at the indicated temperature for $30 \mathrm{~min}$. The error bars represent the standard deviations of triplicate measurements.

that KmAdh1 and KmAdh2 of GX-UN120 are chiefly responsible for the reduction of acetaldehyde to ethanol. KmAdh3 and KmAdh4 catalyze the oxidation reaction of ethanol to acetaldehyde but not the reduction reaction of acetaldehyde to ethanol.

\section{Substrate specificities of the recombinant KmAdhs}

The substrate specificities of the recombinant KmAdhs towards different alcohols with various chain lengths were determined and the results are shown in Figure 7a.
All four KmAdhs preferred ethanol as the best alcoholic substrate. KmAdh1 and KmAdh2 displayed high activities towards primary 1-5 carbon and 1-3 carbon alcohols, respectively, and the activities decreased with increasing chain length. Both enzymes displayed low or no activity for long chain and branched alcohols. KmAdh3 and KmAdh4 displayed high activities towards ethanol and 1-propanol and low activities for other alcohols. The substrate specificities of the KmAdhs towards 16 straight- and branched-chain aliphatic aldehydes with 
Table 1 Summary of enzymatic properties of KmAdhs and ADHs from other yeasts

\begin{tabular}{|c|c|c|c|c|c|c|c|c|}
\hline \multirow[t]{2}{*}{ ADHs } & \multirow{2}{*}{$\begin{array}{l}\text { Optimum } \\
\text { temperature }\left({ }^{\circ} \mathrm{C}\right)\end{array}$} & \multirow{2}{*}{$\begin{array}{l}\text { Optimum } \\
\text { pH }\end{array}$} & \multicolumn{3}{|l|}{ Ethanol } & \multicolumn{3}{|c|}{ Acetaldehyde } \\
\hline & & & $K_{\mathrm{m}}(\mathrm{mM})$ & $K_{\text {cat }}\left(\min ^{-1}\right)$ & $K_{\text {cat }} / K_{\mathrm{m}}\left(\min ^{-1} \mathrm{mM}^{-1}\right)$ & $K_{\mathrm{m}}(\mathrm{mM})$ & $K_{\text {cat }}\left(\min ^{-1}\right)$ & $K_{\text {cat }} / K_{\mathrm{m}}\left(\mathrm{min}^{-1} \mathrm{mM}^{-1}\right)$ \\
\hline $\mathrm{KmAdh} 1^{\mathrm{a}}$ & 50 & 8.0 & 39.7 & $8.5 \times 10^{3}$ & $2.1 \times 10^{2}$ & 4.0 & $1.7 \times 10^{4}$ & $4.3 \times 10^{3}$ \\
\hline $\mathrm{KmAdh}^{\mathrm{a}}$ & 45 & 7.0 & 49.5 & $2.7 \times 10^{2}$ & 5.4 & 1.2 & $3.2 \times 10^{3}$ & $2.7 \times 10^{3}$ \\
\hline $\mathrm{KmAdh}^{\mathrm{a}}$ & 55 & 7.0 & 26.0 & $2.0 \times 10^{3}$ & $0.8 \times 10^{2}$ & n.a. & & \\
\hline $\mathrm{KmAdh} 4^{\mathrm{a}}$ & 45 & 7.0 & 17.0 & $9.5 \times 10^{3}$ & $5.6 \times 10^{2}$ & n.a. & & \\
\hline $\mathrm{KIAdh}^{\mathrm{b}}$ & n.d. & n.d. & 27 & $2.5 \times 10^{5}$ & $9.3 \times 10^{3}$ & 1.2 & $3.6 \times 10^{5}$ & $3.0 \times 10^{5}$ \\
\hline $\mathrm{KIAdh}^{\mathrm{b}}$ & n.d. & n.d. & 23 & $2.8 \times 10^{4}$ & $1.2 \times 10^{3}$ & 1.7 & $3.3 \times 10^{4}$ & $2.0 \times 10^{4}$ \\
\hline KIAdhIII,c & n.d. & n.d. & $0.5-2.6$ & $8.2 \times 10^{4}$ & $3.2 \times 10^{4}$ & $0.1-2.3$ & $8.6 \times 10^{5}$ & $8.6 \times 10^{6}$ \\
\hline KIAdhIV ${ }^{b}$ & n.d. & n.d. & 1.6 & $1.3 \times 10^{4}$ & $8.3 \times 10^{3}$ & 3.1 & $2.9 \times 10^{4}$ & $9.0 \times 10^{3}$ \\
\hline SceAdh $1^{d}$ & 30 & 7.3 & $17-24$ & $2.0 \times 10^{4}$ & $1.2 \times 10^{3}$ & $1.1-3.4$ & $1.0 \times 10^{5}$ & $9.3 \times 10^{4}$ \\
\hline SceAdh $2^{\text {d }}$ & 30 & 7.3 & 0.8 & $7.8 \times 10^{3}$ & $9.6 \times 10^{3}$ & 0.1 & $6.2 \times 10^{4}$ & $6.9 \times 10^{5}$ \\
\hline SceAdh $3^{d}$ & 30 & 7.3 & 12 & n.d. & n.d. & 0.4 & n.d. & n.d. \\
\hline SpAdh $^{d}$ & 30 & 7.3 & 14 & n.d. & n.d. & 1.6 & n.d. & n.d. \\
\hline HpAdh $1^{e}$ & n.d. & n.d. & 0.3 & $2.1 \times 10^{5}$ & $8.4 \times 10^{5}$ & 1.9 & $2.0 \times 10^{5}$ & $1.0 \times 10^{5}$ \\
\hline ScbAdh $1^{f}$ & n.d. & n.d. & 18 & $2.9 \times 10^{4}$ & $1.6 \times 10^{3}$ & 1.1 & $2.1 \times 10^{5}$ & $1.9 \times 10^{5}$ \\
\hline
\end{tabular}

${ }^{\mathrm{a}}$ Data in this study; ${ }^{\mathrm{b}}$ Data from Bozzi et al. [26]; ${ }^{\mathrm{C} D a t a}$ from Brisdelli et al. [27]; ${ }^{\mathrm{d}}$ Data from Ganzhorn et al. [28] and Thomson JM et al. [22]; ${ }^{\mathrm{e} D a t a}$ from Suwannarangsee et al. [21]; ${ }^{f}$ Data from Pal et al. [29]. Kinetic parameters of $\mathrm{KmADH} 1$ for ethanol and acetaldehyde were determined in the presence of $2 \mathrm{mM} \mathrm{NAD}{ }^{+}$or $0.2 \mathrm{mM}$ NADH. KmAdh, ADH of K. marxianus; KIAdh, ADH of K. lactis; SceAdh, ADH of S. cerevisiae; SpAdh, ADH of S. pombe; HpAdh, ADH of H. polymorpha; ScbAdh, ADH of S. carlsbergensis; n.a., no activity detected; n.d., no data available.

various chain lengths and 6 aromatic aldehydes were determined and the results are shown in Figure $7 \mathrm{~b}$. The highest reducing activities of KmAdh1 and KmAdh2 were found with acetaldehyde. KmAdh1 displayed high activities towards most of the straight-chain aliphatic aldehydes and low or no activity towards the branchedchain aliphatic aldehydes and aromatic aldehydes. The substrate specificity of KmAdh2 towards aldehydes was similar to that of KmAdh1. But the substrate specificities of these two ADHs were different when using butyraldehyde, valeraldehyde, heptaldehyde and phenylacetaldehyde as substrates. Regarding KmAdh3 and KmAdh4, no activities were detected towards any of the tested aldehydes.

\section{Discussion}

The mechanism by which $K$. marxianus produces ethanol at high temperature is unknown as yet. Reports about the ethanol metabolic pathway of $K$. marxianus are rare. In particular, the biochemical characteristics of the ADHs from $K$. marxianus, which contribute to ethanol metabolism, are not understood. The growth and ethanol fermentation characteristics suggest that the fermentation capability of $K$. marxianus $\mathrm{GX}-\mathrm{UN} 120$ at $40^{\circ} \mathrm{C}$ is the same as that of $S$. cerevisiae Angel at $34^{\circ} \mathrm{C}$. In the present study, all four ADH-encoding genes of GX-UN120 were cloned and overexpressed in E. coli. The biochemical characteristics of the purified recombinant KmAdhs were investigated. To our knowledge, this is the first report of the heterologous expression of genes encoding the ADHs of K. marxianus.

Amino acid sequence analysis suggests that KmAdh1 and KmAdh2 of GX-UN120 may be cytoplasmic ADHs, while KmAdh3 and KmAdh4 may be mitochondrial ADHs. All four ADHs belong to the microbial group I ADHs. Characterization of their enzymatic properties showed that KmAdhs prefer $\mathrm{NAD}^{+}$and $\mathrm{NADH}$ to $\mathrm{NADP}^{+}$ and NADPH as cofactor, which is similar to ADHs of other yeasts $[25,26,30]$. With optimum temperatures of $45-55^{\circ} \mathrm{C}$ for ethanol and acetaldehyde, the KmAdhs are distinctly different from most reported ADHs of yeasts, which generally have optimum activities at about $30^{\circ} \mathrm{C}$ [28]. Perhaps this is why GX-UN120 produces its maximal yield of ethanol at $40^{\circ} \mathrm{C}$, while other yeasts such as $\mathrm{S}$. cerevisiae and $S$. carlsbergensis have maximal yields usually at $30^{\circ} \mathrm{C}[4,19]$.

There have been no previous reports regarding the substrate specificity of ADHs from $K$. marxianus. Our data indicate that the four recombinant KmAdhs of GXUN120 have a narrow alcoholic substrate specificity, which is similar to ScAdh1 of S. cerevisiae. It was reported that the narrow substrate specificity of ScAdh1 is due to $\mathrm{Met}^{271}$ in its substrate binding cleft, whereas there is a Leu in the corresponding position in other yeast ADHs including KmAdhs [14,31]. The alcoholic substrate specificity of the KmAdhs is similar to that of ScAdh1 but different from that of ScAdh2 [14]. The ADHs of K. lactis [26,27], Adh1 of H. polymorpha [21], ADHs of C. maltosa 


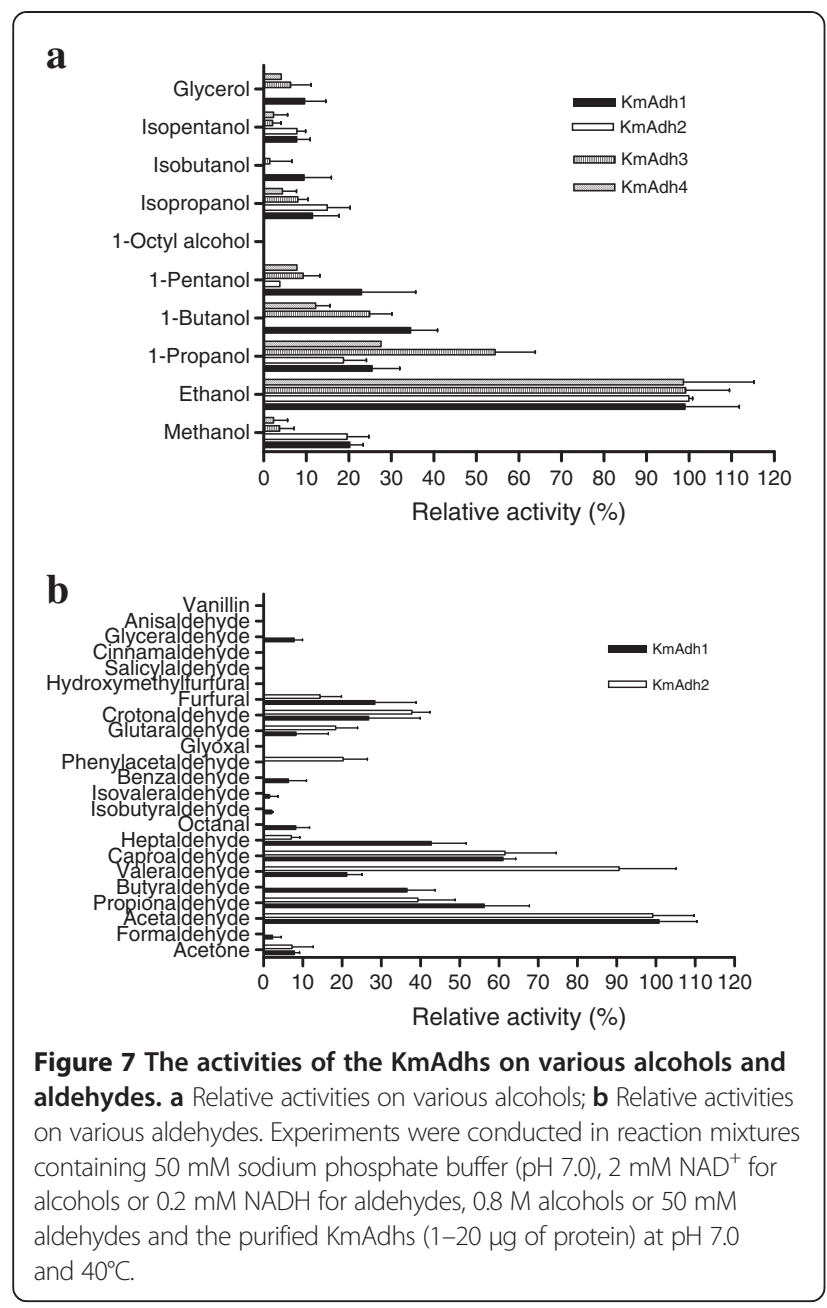

[30] and Adh1 of C. utilis [25] display broad alcoholic substrate specificity. KmAdh1 and KmAdh2 of GX-UN120 have a broad substrate specificity for straight-chain aliphatic aldehydes, and the specific activities towards aldehydes are more than 2-fold higher than those towards the analogous alcohols. These results suggest that KmAdh1 and KmAdh2 prefer aldehydes as their substrates and acetaldehyde was the best substrate, which is similar to ADH1s from other yeasts and KlAdh3 [21,26,27,30]. Interestingly, KmAdh1 and KmAdh2 of GX-UN120 could efficiently reduce furfural, which is formed in the pretreatment of lignocelluloses and is an inhibitor of ethanol production by $S$. cerevisiae. This suggests that GX-UN120 is suitable for use in the SSCF of lignocelluloses to produce ethanol.

\section{Conclusions}

Zymogram analysis showed that KmAdh1 was largely induced in K. marxianus GX-UN120 during ethanol production, KmAdh4 was constitutively expressed at a lower level and KmAdh2 and KmAdh3 were almost undetectable. The genes encoding the four alcohol dehydrogenases were cloned from strain GX-UN120 and heterologous expressed in Escherichia coli. The biochemical characteristics of the recombinant ADHs in this study indicate that KmAdh1 is the primary ADH responsible for the production of ethanol from the reduction of acetaldehyde in K. marxianus. The result that the optimum temperature of KmAdh1 was $20^{\circ} \mathrm{C}$ higher than that of ADH from S. cerevisiae may partially explain the ability of $K$. marxianus to produce ethanol at high temperature.

\section{Methods}

\section{Strains and growth conditions}

K. marxianus GX-UN120 was used in this study and grown in yeast extract, peptone, dextrose (YPD) medium at $37^{\circ} \mathrm{C}$. GX-UN120 is a mutant strain that was derived from the wild-type strain GX-15 which was isolated from soil sample collected in the subtropical area of Guangxi Zhuang Autonomous Region, China [19] and stored in College of Life Science and Technology, Guangxi University, Nanning, China. E. coli DH5 $\alpha$ (Novagen, USA) and Rosetta DE3 (Novagen, USA) strains were used as the hosts for cloning genes and overexpression of recombinant genes and were grown in $\mathrm{LB}$ medium with $100 \mathrm{mg} / \mathrm{L}$ of ampicillin at $37^{\circ} \mathrm{C}$.

\section{Growth and ethanol fermentation of $K$. marxianus and S. cerevisiae}

The growth and ethanol fermentation characteristics of GX-UN120 and S. cerevisiae Angel which was obtained from Angel Yeast Co., Ltd, Yichang, China were investigated in $100 \mathrm{~mL}$ YPD medium containing $20 \mathrm{~g} / \mathrm{L}$ glucose in 250-mL Erlenmeyer flasks or $200 \mathrm{~mL}$ YPD medium containing $150 \mathrm{~g} / \mathrm{L}$ glucose in 500-mL Erlenmeyer flasks. The flasks were incubated without shaking. Growth was measured at $\mathrm{OD}_{600}$ and the ethanol and glucose concentrations were determined by gas chromatography (GC) and high performance liquid chromatography (HPLC), respectively [19].

\section{Table 2 Primers used in this study}

\begin{tabular}{ll}
\hline Primer name & Primer sequence \\
\hline ADH1F & 5'-CGCGGATCCAACACAATGGCTATTCCAGAAACTC-3' \\
ADH1R & 5'-GGCCCAAGCTTTGGAAGTGTCAACGACAATTCTAC-3' \\
ADH2F & 5'-GGAATTCCATATGTCTATTCCAACTACTCAAAAGGG-3' \\
ADH2R & 5'-CCACTCGAGITGGAAGTGTCAACAAC-3' \\
ADH3F & 5'-CGGGATCCATGCTTAGATTAACTAACGCCAG-3' \\
ADH3R & 5'-GGCCCAAGCTTACATAATAGACTTCTCTTCTTCAAGAG-3' \\
ADH4F & 5'-CGGGATCCCCACATTATACTATTAATAAACCAC-3' \\
ADH4R & 5'-GGCCCAAGCTTTAGCATAGCTTAGTTGGACTG-3'
\end{tabular}

The letters italic represented the restriction sites. 


\section{Cloning of genes encoding KmADH from K. marxianus GX-UN120}

The genomic DNA of GX-UN120 was extracted by the standard method [32] and used as the PCR template. The primers for $K m A D H 1$ and $K m A D H 2$ were designed based on the ADH gene sequences of $K$. marxianus ATCC 12424, and those for $K m A D H 3$ and $K m A D H 4$ were based on the ADH gene sequences of DMKU 3-1042 (Table 2). The genes KmADH1, KmADH3 and KmADH4 were amplified by PCR with sense primers ADH1F, ADF3F and ADH4F containing a BamHI restriction site at the $5^{\prime}$ end and antisense primers ADH1R, ADH3R and ADH4R containing a HindIII restriction site at the $5^{\prime}$ end, respectively (Table 2). KmADH2 was amplified with primers ADH2F and ADH2R containing an Nde I and an Xho I restriction site at the $5^{\prime}$ end, respectively (Table 2). The PCR products were purified and ligated with pMD-19 T vector. The resulting recombinant plasmids were transformed into E. coli DH5a competent cells and the confirmed recombinant plasmids containing $K m A D H 1$, $K m A D H 2, K m A D H 3$ and $K m A D H 4$ were named as pGXKmADH1, pGXKmADH2, pGXKmADH3 and pGXKmADH4, respectively.

\section{Expression of $K m A D H$ genes in $E$. coli and purification of the recombinant proteins}

pGXKmADH1, pGXKmADH3, pGXKmADH4 and the expression vector $\mathrm{pET}-32 \mathrm{a}(+)$ were separately digested with BamHI and HindIII and the target fragments were purified. pGXKmADH2 and pET-30a(+) were separately digested with Nde I and Xho I and the gene and the vector DNA were recovered. The DNA fragment containing the KmAdh genes and the corresponding expression vector were ligated with T4 DNA ligase to form pET-32a(+)-KmADH1, pET-30a(+)-KmADH2, pET-32a(+)-KmADH3 and pET$32 \mathrm{a}(+)-\mathrm{KmADH} 4$. The recombinant plasmids were transformed into E. coli Rosetta DE3 to express the target proteins. KmAdh1, KmAdh3 and KmAdh4 were expressed as TrxA fusion proteins [33] and KmAdh2 as a His-tagged protein. The recombinant fusion proteins were purified by co-affinity chromatography using a TALON Cobalt Resin column. The purified, recombinant, fusion KmAdhs were digested with enterokinase light chain to remove the TrxA or His-tag. The digestion mixture was loaded on the TALON Cobalt Resin column. The eluted solution containing KmAdh was collected and used for further study, and the TrxA or His-tag bound to the cobalt resin remained in the column. The native molecular masses of the purified KmAdh proteins were measured by high performance gel permeation chromatography (HPGPC) using a Macrosphere GPC $1507 \mu$ column $(250 \mathrm{~mm} \times 4.6 \mathrm{~mm}$, Alltech Associates, Inc.) and eluted with $0.15 \mathrm{M} \mathrm{NaCl}$ at a flow rate of $0.3 \mathrm{~mL} / \mathrm{min}$. The molecular masses were then calculated using the protein molecular weight standards ferritin horse $(450 \mathrm{kDa})$, catalase bovine $(240 \mathrm{kDa})$, aldolase rabbit $(160 \mathrm{kDa})$ and albumin bovine $(67 \mathrm{kDa})$ (SERVA Electrophoresis GmbH, Heidelberg, Germany).

\section{Enzyme assay}

The zymogram analysis of $\mathrm{ADH}$ isozymes and the $\mathrm{ADH}$ activities were assayed according to the method previously described by Cho and Jeffries [34] with minor modification. The reaction mixture contained $50 \mathrm{mM}$ sodium phosphate buffer (pH 7.0), $2 \mathrm{mM} \mathrm{NAD}^{+}$or $0.2 \mathrm{mM} \mathrm{NADH}, 0.8 \mathrm{M}$ alcoholic substrates or $50 \mathrm{mM}$ aldehydic substrates and the purified KmAdhs. One enzyme unit (U) was defined as the micromoles of NADH produced or consumed per minute.

\section{Kinetic analysis}

Kinetic analysis of the KmAdhs was performed as previously described [27]. The $K_{\mathrm{m}}$ and $V_{\max }$ values were measured using the double-reciprocal plot method of Lineweaver-Burk [35]. Catalytic efficiency $\left(k_{\mathrm{cat}} / K_{\mathrm{m}}\right)$ was derived from $V_{\max } / K_{\mathrm{m}}[E]$.

\section{DNA sequence analysis}

Sequence assembly and ORF analysis were carried out using the Vector NTI program. The protein sequence similarity searches were performed with the BLAST tools (www.ncbi.nlm.nih.gov). Only proteins that showed significant similarity and had already been characterized as $\mathrm{ADH}$ were used for phylogenetic analysis and multiple sequence alignment. The nucleotide sequences of $K m A D H 1$, $K m A D H 2, K m A D H 3$ and $K m A D H 4$ were deposited in the GenBank database under accession numbers KF678864, KF678866, KF678865, KF678867, respectively.

\section{Additional file}

Additional file 1: Table S1. The alcohol dehydrogenase sequences

used in this study.

\section{Competing interests}

The authors declare that they have no competing interests.

\section{Authors' contributions}

$J J \mathrm{~L}$ participated in the design of the study, performed all the experiments, analysed the data and wrote the manuscript. MLZ participated in the research of KmAdh3. MD participated in the research of KmAdh4. ZMM participated in the research of KmAdh1. SXW participated in the research of KmAdh2. YD participated in the research of the growth and ethanol fermentation of the strain. JXF participated in the design of the study and commented on the manuscript. All authors read and approved the final manuscript.

\section{Acknowledgements}

This work was financially supported by a grant from the Guangxi Natural Science Foundation (2012GXNSFGA060005), and the Bagui Scholar Program of Guangxi (2011A001)

Received: 6 November 2013 Accepted: 12 May 2014

Published: 21 May 2014 
References

1. Lane MM, Morrissey JP: Kluyveromyces marxianus: a yeast emerging from its sister's shadow. Fungal Biol Rev 2010, 24:17-26.

2. Schaffrath R, Breunig KD: Genetics and molecular physiology of the yeast Kluyveromyces lactis. Fungal Genet Biol 2000, 30:173-190.

3. Fonseca GG, Heinzle E, Wittmann C, Gombert AK: The yeast Kluyveromyces marxianus and its biotechnological potential. Appl Microbiol Biotechnol 2008, 79:339-354.

4. Nonklang S, Abdel-Banat BMA, Cha-aim K, Moonjai N, Hoshida H, Limtong S, Yamada M, Akada R: High-temperature ethanol fermentation and transformation with linear DNA in the thermotolerant yeast Kluyveromyces marxianus DMKU3-1042. Appl Environ Microbiol 2008, 74:7514-7521

5. Wilkins MR, Mueller M, Eichling S, Banat IM: Fermentation of xylose by the thermotolerant yeast strains Kluyveromyces marxianus IMB2, IMB4, and IMB5 under anaerobic conditions. Process Biochem 2008, 43:346-350.

6. Anderson PJ, McNeil K, Watson K: High-efficiency carbohydrate fermentation to ethanol at temperatures above $40^{\circ} \mathrm{C}$ by Kluyveromyces marxianus var. marxianus isolated from sugar mills. Appl Environ Microbiol 1986, 51:1314-1320.

7. Banat IM, Nigam P, Marchant R: Isolation of thermotolerant, fermentative yeasts growing at $52^{\circ} \mathrm{C}$ and producing ethanol at $45^{\circ} \mathrm{C}$ and $50^{\circ} \mathrm{C}$. World J Microbiol Biotechnol 1992, 8:259-263.

8. Bai FW, Anderson WA, Moo-Young M: Ethanol fermentation technologies from sugar and starch feedstocks. Biotechnol Adv 2008, 26:89-105.

9. Ballesteros M, Oliva JM, Negro MJ, Manzanares P, Ballesteros I: Ethanol from lignocellulosic materials by a simultaneous saccharification and fermentation process (SSF) with Kluyveromyces marxianus CECT 10875. Proc Biochem 2004, 39:1843-1848.

10. Tomás-Pejó E, García-Aparicio M, Negro MJ, Oliva JM, Ballesteros M: Effect of different cellulase dosages on cell viability and ethanol production by Kluyveromyces marxianus in SSF processes. Bioresour Technol 2009, 100:890-895.

11. de Smidt O, du Preez JC, Albertyn J: The alcohol dehydrogenases of Saccharomyces cerevisiae: a comprehensive review. FEMS Yeast Res 2008, 8:967-978.

12. Lertwattanasakul N, Sootsuwan K, Limtong S, Thanonkeo P, Yamada M: Comparison of the gene expression patterns of alcohol dehydrogenase isozymes in the thermotolerant yeast Kluyveromyces marxianus and their physiological functions. Biosci Biotechnol Biochem 2007, 71:1170-1182.

13. Saliola M, Shuster JR, Falcone C: The alcohol dehydrogenase system in the yeast, Kluyveromyces lactis. Yeast 1990, 6:193-204.

14. Shain DH, Salvadore C, Denis CL: Evolution of the alcohol dehydrogenase $(\mathrm{ADH})$ genes in yeast: characterization of a fourth $\mathrm{ADH}$ in Kluyveromyces lactis. Mol Gen Genet 1992, 232:479-488

15. Jeong H, Lee DH, Kim SH, Kim HJ, Lee K, Song JY, Kim BK, Sung BH, Park JC, Sohn JH, Koo HM, Kim JF: Genome sequence of the thermotolerant yeast Kluyveromyces marxianus var. marxianus KCTC 17555. Eukaryot Cell 2012, 11:1584-1585.

16. Ladrière JM, Delcour J, Vandenhaute J: Sequence of a gene coding for a cytoplasmic alcohol dehydrogenase from Kluyveromyces marxianus ATCC 12424. Biochim Biophys Acta 1993, 1173:99-101.

17. Ladrière JM, Georis I, Guèrineau M, Vandenhaute J: Kluyveromyces marxianus exhibits an ancestral Saccharomyces cerevisiae genome organization downstream of ADH2. Gene 2000, 255:83-91.

18. Lertwattanasakul N, Shigemoto E, Rodrussamee N, Limtong S, Thanonkeo P, Yamada M: The crucial role of alcohol dehydrogenase Adh3 in Kluyveromyces marxianus mitochondrial metabolism. Biosci Biotechnol Biochem 2009, 73:2720-2726.

19. Pang Z-W, Liang J-J, Qin X-J, Wang J-R, Feng J-X, Huang R-B: Multiple induced mutagenesis for improvement of ethanol production by Kluyveromyces marxianus. Biotechnol Lett 2010, 32:1847-1851.

20. Bennetzen JL, Hall BD: The primary structure of the Saccharomyces cerevisiae gene for alcohol dehydrogenase. J Bio/ Chem 1982, 257:3018-3025.

21. Suwannarangsee S, Oh DB, Seo JW, Kim CH, Rhee SK, Kang HA, Chulalaksananukul W, Kwon O: Characterization of alcohol dehydrogenase 1 of the thermotolerant methylotrophic yeast Hansenula polymorpha. Appl Microbiol Biotechnol 2010, 88:497-507.

22. Thomson JM, Gaucher EA, Burgan MF, De Kee DW, Li T, Aris JP, Benner SA: Resurrecting ancestral alcohol dehydrogenases from yeast. Nat Genet 2005, 37:630-635.
23. Young ET, Sloan J, Miller B, Li N, van Riper K, Dombek KM: Evolution of a glucose-regulated ADH gene in the genus Saccharomyces. Gene 2000, 245:299-309.

24. Jornvall $H$, Eklund $H$, Branden $\mathrm{Cl}$ : Subunit conformation of yeast alcohol dehydrogenase. J Biol Chem 1978, 253:8414-8419.

25. Park YC, Yun NR, San KY, Bennett GN: Molecular cloning and characterization of the alcohol dehydrogenase ADH1 gene of Candida utilis ATCC 9950. J Ind Microbiol Biotechnol 2006, 33:1032-1036.

26. Bozzi A, Saliola M, Falcone C, Bossa F, Martini F: Structural and biochemical studies of alcohol dehydrogenase isozymes from Kluyveromyces lactis. Biochim Biophys Acta 1997, 1339:133-142.

27. Brisdelli F, Saliola M, Pascarella S, Luzi C, Franceschini N, Falcone C, Martini F, Bozzi A: Kinetic properties of native and mutagenized isoforms of mitochondrial alcohol dehydrogenase III purified from Kluyveromyces lactis. Biochimie 2004, 86:705-712

28. Ganzhorn AJ, Green DW, Hershey AD, Gould RM, Plapp BV: Kinetic characterization of yeast alcohol dehydrogenases. Amino acid residue 294 and substrate specificity. J Biol Chem 1987, 262:3754-3761.

29. Pal S, Park DH, Plapp BV: Activity of yeast alcohol dehydrogenases on benzyl alcohols and benzaldehydes: characterization of ADH1 from Saccharomyces carlsbergensis and transition state analysis. Chem Biol Interact 2009, 178:16-23.

30. Lin Y, He P, Wang Q, Lu D, Li Z, Wu C, Jiang N: The alcohol dehydrogenase system in the xylose-fermenting yeast Candida maltosa. PLoS One 2010, 5:e11752.

31. Eklund $\mathrm{H}$, Branden $\mathrm{Cl}$, Jornvall $\mathrm{H}$ : Structural comparisons of mammalian, yeast and bacillar alcohol dehydrogenases. J Mol Biol 1976, 102:61-73.

32. Sambrook J, Russell DW: Molecular cloning: a laboratory mannual. 3rd ed. Cold Spring Harbor, New York: Cold Spring Harbor Laboratory Press; 2001.

33. LaVallie ER, DiBlasio EA, Kovacic S, Grant KL, Schendel PF, McCoy JM: A thioredoxin gene fusion expression system that circumvents inclusion body formation in the E. coli cytoplasm. Nat Biotechnol 1993, 11:187-193.

34. Cho JY, Jeffries TW: Transcriptional control of ADH genes in the xylosefermenting yeast Pichia stipitis. Appl Environ Microbiol 1999, 65:2363-2368.

35. Lineweaver $H$, Burk D: The determination of enzyme dissociation constants. J Am Chem Soc 1934, 56:658-666.

doi:10.1186/1472-6750-14-45

Cite this article as: Liang et al:: Alcohol dehydrogenases from Kluyveromyces marxianus: heterologous expression in Escherichia coli and biochemical characterization. BMC Biotechnology 2014 14:45.

\section{Submit your next manuscript to BioMed Central and take full advantage of:}

- Convenient online submission

- Thorough peer review

- No space constraints or color figure charges

- Immediate publication on acceptance

- Inclusion in PubMed, CAS, Scopus and Google Scholar

- Research which is freely available for redistribution 